\begin{tabular}{l} 
RCCS \\
\hline Annual Review
\end{tabular}

\section{RCCS Annual Review}

A selection from the Portuguese journal Revista Crítica de Ciências Sociais

$6 \mid 2014$

Issue no. 6

\title{
The Political Economy of Consumption and Household Debt: An Interdisciplinary Contribution
}

Ana Cordeiro Santos, Vânia Costa and Nuno Teles

Translator. Sheena Caldwell

\section{(2) OpenEdition}

\section{Journals}

Electronic version

URL: http://journals.openedition.org/rccsar/537

DOI: $10.4000 /$ rccsar.537

ISSN: $1647-3175$

\section{Publisher}

Centro de Estudos Sociais da Universidade de Coimbra

Electronic reference

Ana Cordeiro Santos, Vânia Costa and Nuno Teles, «The Political Economy of Consumption and Household Debt: An Interdisciplinary Contribution », RCCS Annual Review [Online], 6 | 2014, Online since 01 October 2014, connection on 30 April 2019. URL : http://journals.openedition.org/rccsar/537 ; DOI : $10.4000 /$ rccsar.537 
Ana Cordeiro Santos, Vânia Costa, Nuno Teles

Centre for Social Studies, University of Coimbra, Portugal

\title{
The Political Economy of Consumption and Household Debt: An Interdisciplinary Contribution $^{*}$
}

\begin{abstract}
This article offers a critical review of the literature on consumption and household debt, with the aim of identifying the main contributions and drawbacks of disciplinary approaches for understanding the multiple factors that influence these important forms of socioeconomic behaviour. On the basis of this literature review, the authors propose an interdisciplinary line of research within political economy that places particular emphasis on structural factors such as the recent transformations in contemporary capitalism, which have led to an extraordinary growth in the economic and political power of finance. It also foregrounds relevant social changes such as the increasing dominance of the neoliberal ideology, which promotes an individualisation of the provision of goods and services that favours the financial sector.
\end{abstract}

Keywords: consumer; consumer behaviour; consumer credit; personal finances; consumer society.

\section{The fragmentation of the study of consumption and household debt}

Given its importance in contemporary societies, consumption is nowadays a subject in its own right in various fields of the social sciences. This recognition has coincided with the emergence of consumer behaviour studies, which has sought to establish itself as an interdisciplinary field, in particular since the 1970s. Household debt, on the other hand, has been a subject of recent interest, stimulated by the financial crisis of 2007-2008 which highlighted the relationship between decision-making, household behaviour and the functioning of the financial system.

Research into consumer behaviour and the so-called consumer society is, however, very segmented. Approached from the prevailing perspectives in each discipline, this study foregrounds their theoretical and methodological preferences. In focussing on the individual, psychology, for example, studies the way in which consumers process information about products traded on the market and make decisions which are to a greater or lesser extent deliberate. Sociology, on the other hand, has highlighted the symbolic content of consumer products and their role in affirming the status or social position of various classes or social

\footnotetext{
* Article published in RCCS 101 (September 2013).

The authors would like to thank the two anonymous referees for their comments and suggestions which were very helpful in improving this article, whilst assuming responsibility for any errors or omissions that may remain. They also wish to acknowledge the financial support received from the Foundation for Science and Technology under the BEHAVE project (PTDC/PSI-PSO/114257/2009 - FCOMP-01-0124-FEDER-015552).
} 
groups. Even the approaches that aim to transcend disciplinary constraints fall victim to this rigid compartmentalisation, revealing the dominance of certain disciplinary fields.

Although, taken as a whole, these analyses have the merit of exposing the complexity and range of factors that determine consumption - ranging from sociological variables such as social status to psychological variables such as attitudes and habits, or cultural variables such as taste and meaning - they have nevertheless failed to promote any genuinely inter- or transdisciplinary dialogue (Fine and Leopold, 1993; Fine, 2002).

This article argues that the political economy approach favours this dialogue among the social sciences, allowing for a more wide-ranging analytical framework in which structural transformations are interlinked to important cultural changes that are highly relevant to the analysis of consumer decision-making and behaviour and household debt.

In the classical tradition ranging from Adam Smith to Karl Marx, amongst others, political economy is conceived of as the interdisciplinary study of the economy which positions it within its social and political context, thus taking into consideration the power structures which determine the way in which resources are produced and distributed amongst the various social classes, as well as the cultural environment, assuming that relationships based on production and exchange at any given historical moment always contain the potential to transform underlying values and social norms. The approach of political economy therefore contrasts with that of conventional economics, which isolates the economy from its social and political context, thus distancing itself from the other social sciences. It does so by adopting methodological individualism, taking the individual as the elementary unit of analysis, disregarding social categories such as class and structure, and endorsing abstract, universally applicable principles such as the utility maximisation principle, thus ignoring the specific nature of the decision-making problem as well as its social and political context and relegating them to the realm of other social sciences. It also reduces the scope of analysis to market supply and demand, seeing markets as neutral, homogeneous and indistinct mechanisms for allocating resources that require no consideration of the social and political context in which they operate (see Milonakis and Fine, 2009).

These weaknesses in conventional economics are very evident in its analysis of consumption and household debt. Although they are central analytical categories, conventional economic theory has not paid sufficient attention to these important forms of economic behaviour, reducing each and every consumer act, as well as recourse to credit, to 
a standard problem of individual utility maximisation. As will later be seen, although contributions from other social sciences, namely psychology, have been incorporated into the research programme of the recently established field of behavioural economics, these developments have not contributed to any significant change in the conceptual and normative framework of the dominant approach. Thus, such developments still do not provide the analytical resources needed to establish a productive dialogue with the other social sciences, which would, in turn, contribute towards a broader vision of consumption and household debt.

Perhaps as a result of this lack of interest on the part of mainstream economics, together with its greater emphasis on the sphere of production, heterodox economics has also failed to study consumption and household debt in a systematic way. ${ }^{1}$ It is only very recently that some approaches within political economy have addressed the developing relationships between households and the financial sector as part of a broader phenomenon that has been generically termed financialisation (Ertuk et al., 2007; dos Santos, 2009; Lapavitsas, 2009; Montgomerie, 2009). The study of consumption and debt is therefore in a very embryonic phase, having identified major trends without grounding this in any deeper analysis of the relationship between the two phenomena, the various forms it assumes in different contexts and their impact on different social groups.

This article provides a critical review of the literature, aiming to identify the main contributions and drawbacks of the approaches used by the various disciplines to understand the multiple factors which influence consumption and household debt. On the basis of this literature review, it proposes a line of interdisciplinary research within the framework of political economy that is capable of identifying the factors and relationships which, if analysed in greater depth, would contribute towards a more accurate understanding of consumption and household debt.

\section{The isolation of the conventional economics approach to analysing consumption and household debt}

The origins of consumer theory, stemming from the conventional economics approach, dates back to the Marginalist school of thought in the $19^{\text {th }}$ century which saw human beings

\footnotetext{
${ }^{1}$ Naturally there are exceptions, particularly in the common ground between sociology and economics, as will be seen later.
} 
as individual utility maximising agents. Given a certain set of tastes or preferences, income and price of goods, the problem facing the consumer was that of composing the basket of goods that would maximize his/her individual wellbeing. This decision-making problem was not distinguished from other economic problems, namely decisions made by producers who, given a particular budget allocation, level of technology and prices for raw materials and outputs (which are assumed to be defined under competitive conditions), aim, in the same way, to choose the level of production that will enable them to maximize profits. In other words, as Fine and Leopold note (1993: 46), economic science has not presented a genuine theory of consumption that can reveal its specific nature and distinguish it from the sphere of production. The utility maximisation principle is applied to any agent, each and every decision, all types of goods and any period of time.

The rationality assumption, i.e. the notion that agents are effectively capable of maximising their wellbeing, in turn dismisses both the process of decision-making and the determinants of consumption as irrelevant. Whilst, on the one hand, elements which are not explained by the theory of rational choice are considered only minor 'deviations' from standard behaviour and therefore of no interest to economics, the subjectivist concept of utility, evident in the expression "De gustibus non est disputandum" ("there is no accounting for taste") popularised in an influential article by George Stigler and Gary Becker (1977), prevents any discussion of the choices made. This means that any analysis of the process of creating preferences remains outside the sphere of economics and is considered an individual matter, independent of previous or later consumer decisions and behaviour. Individual decision-making processes are also excluded, since optimising behaviour is assumed, as well as activities dedicated to acquiring and enjoying commodities. The disregard for all these aspects, given its heavily reductionist nature, explains the selfexclusion of economics from attempts at building a genuinely interdisciplinary theory of consumption, as well as less demanding multidisciplinary endeavours (Fine and Leopold, 1993).

Decisions concerning credit and long-term consumption are also approached as a problem of individual utility maximisation. According to the life-cycle hypothesis (Modigliani and Brumberg, 1954), consumers aim to ensure a uniform level of consumption throughout their lives. This (and, by implication, savings) is determined at any given moment by current wealth and income, expectations of their future evolution and life expectancy. This theory 
therefore envisages that individuals save during periods of high income (in middle age) and resort to debt and savings at times when their income is lower (at the beginning of their working life and after retirement). From this perspective, indebtedness at the beginning of a career is rational, since the expectation of a rise in income during the course of professional life will enable individuals to support the burden of debt and, at a certain point, start saving for their retirement.

Similarly, the permanent income hypothesis (Friedman, 1957) also assumes that consumption depends on expectations relating to the total income (not current disposable income) which individuals expect to earn during their lives, and that the temporary fluctuations it may experience have no impact on consumption. From this point of view, individuals consume a steady proportion of their permanent income, determined by their wealth and level of education, which in turn depend on their individual capacity to generate income during their lives. Even though it does not indicate the point at which it is rational to resort to credit, as the life-cycle hypothesis does, it is once again assumed that indebtedness is the result of a rational decision aimed at maximising intertemporal utility, now based on the wealth and income expected during the life cycle.

These analyses offer abstract arguments which aim to justify the rationality of credit and consumption decisions, whilst disregarding contextual and historical factors. They also ignore the fact that the relationship between households and the credit market depends on countless conditions, such as the criteria for granting loans, which make them inaccessible to certain households (for example, ownership of assets that may serve as collateral), or intrinsic uncertainty surrounding future income, which restrains individuals and households from entering into debt (Levine and Kehoe, 2001).

The increasing involvement of individuals and households in the financial markets as small investors has in turn stimulated a recent interest in individual financial decision-making and has led to a new line of research known as household finance (Campbell, 2006; Guiso and Sodini, 2012). Once again it can be seen that the analysis of individual financial decisionmaking involves applying conventional theoretical resources to new problems, such as the portfolio theory whose seminal contributions date back to the work of Harry Markowitz (1952) and James Tobin (1958), originally designed to describe the behaviour of financial analysts, not individuals and households. According to these models, financial investors, including both professional investors and ordinary citizens, as rational agents, should choose 
a portfolio of financial assets according to their preferences (determined by a greater or lesser aversion to risk), thus maximising individual utility.

In terms of credit decisions, recent work has focussed on analysing the isolated effect of replacing certain assumptions contained in the intertemporal consumption model (e.g. composition of the household, socio-demographic characteristics, uncertainty regarding the future, constraints on liquidity), whilst continuing to regard consumption and, indirectly, credit, as a problem of optimisation subject to restrictions (Bertola et al., 2006). Credit is still seen as a mere instrument, although a necessary and desirable one, for maintaining a stable pattern of consumption throughout the life cycle of individuals, allowing for redistribution between periods of high and low income. From this point of view, it is rational to enjoy higher levels of consumption than the disposable income permits by resorting to savings or credit. This means that conventional economics not only fails to distinguish between consumption and production, but also between consumer decisions and credit decisions, viewing the latter as part of consumer decision-making, whose main determinant is income.

Supported by ideas of rationality and market efficiency that are central to conventional economics, rising household debt in the most developed capitalist economies during the past two to three decades has been interpreted as the result of rational decisions made by consumers who know how to take advantage of easier access to credit at a historically low cost, following the significant expansion of credit after decades of financial liberalization and technological innovation in the sector. Rational consumers, guided by intertemporal preferences, simply responded to new economic incentives (for a critical analysis, see Ertuk et al., 2007; Barba and Pivetti, 2008; Crotty, 2009; Cynamon and Fazzari, 2008).

The collapse of the US subprime market which had targeted the low-income sections of the population and the spread of its effects to financial markets throughout the world in 2007-2008 disturbed the dominant discourse. ${ }^{2}$ From the above, it is perhaps not surprising that this theoretical framework contributed to an evaluation of the financial crisis as partially caused by behaviour which deviated from the norms of rationality, namely an incorrect assessment of the risks associated with credit. However, as will later be seen, other

\footnotetext{
${ }^{2}$ Whilst this market segment refers mainly to loans for purchasing homes, the severity and extent of its effects have led to calls for attention to rising household debt, in total and itemized, over the last two to three decades.
} 
theoretical perspectives that take the historical context of contemporary capitalist societies into account offer alternative explanations.

\section{Behavioural economics: the dialogue with psychology and the selective revision of behavioural assumptions}

Psychology also approaches consumption from the point of view of the individual. However, this discipline adopts a broader perspective, both with regard to human rationality and the motives underlying the choice of a wide range of consumer goods. Rather than restricting consumer behaviour to utility maximisation, psychology seeks to identify the multiple factors that influence choice and is interested in the various decision-making processes, ranging from deliberate choices, based on calculating the costs and benefits of the various available options, to more impulsive forms of behaviour.

These multiple approaches and areas of research reflect an interest that has its origins in the emergence of the discipline at the end of the $19^{\text {th }}$ century and its establishment in the first half of the previous century, up to the founding, in the 1960s, of consumer psychology as branch of applied psychology. One illustration of this is the creation, in 1962, of the Consumer Psychology Division within the American Psychological Association and the publication during this period of textbooks on consumer behaviour which would define teaching and research in the field (cf. Schumann et al., 2008). This area of study was finally consolidated with the launch, in 1992, of The Journal of Consumer Psychology, dedicated to publishing research which "applies the perspectives of psychology to the study of the consumer," thus replicating its lines of research in this area (e.g. judgement and decisionmaking processes, the affective, cognitive and motivational determinants of behaviour and attitude formation and change, amongst others). ${ }^{3}$

However, in the recent state-of-the-art review in the Handbook of Consumer Psychology, perhaps reflecting the growing influence of consumer behaviour studies, this research programme is presented as an area which combines psychology, marketing and advertising, whose objective is to contribute towards "a better scientific understanding of cognitive, affective, and behavioural responses to products and services, the marketing of these products and services, and societal and ethical concerns associated with marketing processes" (Haugtevedt et al., 2008: ix).

\footnotetext{
${ }^{3}$ Consulted on 02.04.2013, at http://www.journals.elsevier.com/journal-of-consumer-psychology.
} 
In fact, under the auspices of the Association for Consumer Research, the field of consumer behaviour was officially founded in 1969, seeking to combine contributions from various disciplines, namely psychology, sociology, anthropology, economics, linguistics, critical theory and statistics, which share the same research objectives. ${ }^{4}$ Despite its openness to contributions from various disciplinary backgrounds, this area of study did not establish itself as an inter- or transdisciplinary field. On the contrary, consumer behaviour studies remains multidisciplinary, accepting contributions from a variety of disciplines, which makes it fragmented in nature. It is defined, in general terms, as the analysis of consumer behaviour, namely the acquisition, enjoyment and display of market products and services and the experiences associated with these activities (Macinnis and Folkes, 2010).

There is, however, a presumption that this multidisciplinary area is mainly influenced by marketing. Efforts to establish the field of consumer studies were, in fact, part of a strategy designed to separate this programme from negative associations with marketing, although the latter still remained one of the key areas behind the programme (ibidem). However, its disciplinary background is evident in the main lines of research, namely psychology, economics, sociology and anthropology, which include the following: information processing (including analysis of emotions, attitudes, memory and conscious and unconscious processes), behavioural decision theory (including neuroeconomics, the heuristics and biases programme, intertemporal choice, normative decision-making and judgement under uncertainty) and, finally, consumer culture theory (encompassing questions of identity, marketplace cultures and ideologies and socio-historical influences) (ibidem). Fine and Leopold's claim that research in this area reflects separate applications of the individual disciplinary traditions therefore seems accurate, with each operating as isolated Kuhnian paradigms to the extent that the nature and the explanation of consumer behaviour is understood differently by the various disciplines (1993: 41).

It should also be noted that credit is not identified as a relevant topic in any of these critical reports or in studies on consumer behaviour and overviews of the recent evolution of consumer psychology. The fact that none of the 47 entries in the Handbook of Consumer Psychology deals with the subject of credit speaks for itself. However, contributions from psychology can be found in the behavioural economics research programme, which aims to incorporate more realistic assumptions concerning human behaviour into the economic

\footnotetext{
${ }^{4}$ Consulted on 02.04.2013, at http://www.acrwebsite.org/web/about-acr/acr-history.aspx.
} 
analysis, linking consumption and recourse to credit in its research into intertemporal decision-making.

The seminal studies on behavioural economics date back to the 1970s and the work of Daniel Kahneman and Amos Tversky and other psychologists such as Paul Slovic (Kahneman and Tversky, 1979; Tversky and Kahneman, 1974; Kahneman, Slovic and Tversky, 1982), dedicated to empirical and primarily experimental testing of behavioural assumptions of conventional economic theory, namely the expected utility hypothesis and the discounted utility hypothesis, which aimed to provide "a theoretical framework that can be applied to almost any form of economic (and even non-economic) behaviour, and makes refutable predictions" (Camerer and Loewenstein, 2004: 3).

This research presented a very significant set of behavioural patterns which systematically diverged from the presuppositions and predictions of conventional economic theory, understood in the literature as behavioural 'anomalies'. ${ }^{5}$ According to Tversky and Kahneman (1974), many of the errors identified in the calculation of the probability of future events are due to the use of heuristic procedures, i.e. rules which simplify and facilitate the decision-making process but sometimes lead to failures which are systematically repeated, identifying three important heuristic categories: representativeness, availability and anchoring. ${ }^{6}$ These errors may also be due to a wide range of factors which interfere with choice, such as the language used to describe the problem of decision-making (known as framing) (Tversky and Kahneman, 1981). ${ }^{7}$ These findings were later formalised in prospect theory, a descriptive theory of decision-making in situations of risk which emphasises the influence of the status quo and other reference points for individual choice (Kahneman and Tversky, 1979).

Of particular relevance to this discussion is the analysis of intertemporal choice, which refers to all decisions whose effects are distributed across a relatively broad time horizon, with consumption and credit naturally forming part of these decisions (Loewenstein and Thaler, 1989). According to the discounted utility model, the decision-maker aims to

\footnotetext{
${ }^{5}$ This research led to the "Anomalies" column published in the prestigious Journal of Economic Perspectives between 1987 and 1990, later systematized in Thaler (1992).

${ }^{6}$ For example, the heuristics of availability means that people are often influenced by information that is more easily selected by memory, such as information relating to recent events, rather than other relevant factors such as the frequency of these events.

${ }^{7}$ For example, people react differently according to how clearly the decision-making problem reveals the associated losses or gains, with a greater propensity to risk evident in contexts in which the losses are more salient.
} 
maximise total utility through consumption on a temporal horizon associated with the decision-making problem (which, unlike the life-cycle and permanent income hypotheses, does not have to coincide with the consumer's life cycle). This model assumes that individuals prefer consuming in the present rather than in the future, which implies that consumption of a particular commodity in the future provides a lesser degree of utility, and this is discounted at a constant rate which expresses the individual intertemporal preference. The model offers an explanation of consumption which is independent of (present and future) income and, indirectly, of credit, and is based on an additional set of assumptions, such as the presumption that the utility obtained within a given period is independent of the utility in other periods (meaning that the consumer has no preference for a stable or varying pattern of consumption if the sum total of utility remains the same), or that intertemporal preference is independent of the type of goods (meaning that consumers apply the same discounted rate to all consumer goods) (Frederick et al., 2002).

The results of various laboratory experiments and other empirical studies show that a large part of these assumptions have no empirical basis, revealing that intertemporal choice is affected by a varying set of factors depending on the type of consumer goods, the time horizon associated with the decision, the way in which the decision is presented (the framing effect), the individual starting point (the endowment effect), the characteristics of decisionmakers, etc. (ibidem).

One of the most significant results is the apparent conflict between short- and long-term preferences, which may result in dynamically inconsistent choices. In other words, although they reveal a desire to commit to long-term plans that imply some sacrifice in the present (for example, saving implies renouncing consumption in the present), difficulties in pursing these objectives in the long term are frequently encountered (i.e. people consume when they plan to save). On the basis of these results, Laibson (1997) suggests that individuals follow the hyperbolic discount model in which results in the near future are discounted more than results in the distant future (i.e. the discount rate diminishes over time), which may lead to regret at not having adopted the desired course of action from a long-term perspective.

This interpretation is, nevertheless, open to question. Loewenstein (1996) and his coauthors (Loewenstein et al., 2003) attribute the apparent intertemporal inconsistency to the interference of visceral factors (such as emotion and pain) which, in certain circumstances, 
make people particularly vulnerable to impulsive behaviour. From this perspective, the apparently inconsistent behaviour is due to the effect of contextual and momentary factors rather than a genuine change of preferences. Moreover, other studies have emphasised that some individuals are able to remain true to their long-term plans, even revealing a sense of anticipation, and protect themselves against likely problems of self-control by committing in advance to a particular course of action. One example of this is the purchase of illiquid assets as a means of containing current expenditure (e.g. house buying), or strategies that avoid exposure to temptation (such as not owning a credit card) (Laibson 1997, 1998). From this perspective, recourse to housing loans may represent an "enforced savings" mechanism for households, even though it involves a particular cost (interest payable) and not a gain (interest receivable), unlike savings products.

Another mechanism commonly used to deal with this type of problem is 'mental accounting', which involves the differentiated categorisation of sources of income and expenditure. According to Shefrin and Thaler (1988), people distribute their income into three separate mental accounts: current income, derived from work; current assets, the return on capital; and future income which, as its name suggests, refers to income expected to be obtained in the future from work or savings. As each account is associated with expenditure and rules for use, individuals manage to pursue different objectives, using the current income account for consumer spending whilst preserving the other accounts. This research has inspired various proposals, such as "Save More Tomorrow" by Thaler and Benartzi (2004), which channels part of the future income of workers into a pension fund for use on retirement. The proposal aims to resolve inconsistencies in behaviour, drawing on conventional economics but involving a different understanding of consumption and credit. It is now assumed that consumer decisions and consequently recourse to credit are not necessarily rational but may nevertheless be corrected by (voluntary) mechanisms which discipline individual behaviour.

Similarly, but focussing on the role of the socio-cultural context of the most advanced capitalist economies, analyses from the field of anthropology and sociology also emphasise the role of self-discipline, partly attributing this to representations of consumption in contemporary culture, which stress the benefits of planned consumption whilst also legitimizing occasional hedonism. Consumption, savings and self-control should therefore be understood within a broader framework, since "these problematics are as rooted in the 
economy, society, and culture of contemporary capitalism as they are in the human mind" (Starr, 2007: 277). Following the same line of argument, various authors have noted the selfdisciplinary role, if not social control, of credit, stressing that household debt intensifies the dependency of the salaried worker as a result of assuming a medium/long-term commitment to creditors (Calder, 1999; Langley, 2008). As Lendol Calder states, "if there is hedonism in consumer culture, it is a disciplined hedonism" (1999: 31).

These contributions from the fields of anthropology and sociology suggest productive lines of research for the interaction between decision-making and the socio-cultural environment, questioning interpretations which view individual and household debt as the result of inadequate individual choices. Although the analytical framework for behavioural economics is malleable enough to accommodate contextual factors, preserving the concept of rationality restricts the assessment of deviations from assumptions and theoretical predictions to errors of calculation. The argument that rising household debt is due to greater difficulty in exercising self-control, given easier access to forms of "instant" credit such as credit cards, is illustrative of this (Laibson, 1997). In short, these additions to the dominant theoretical framework appear to constitute a selective form of appropriation which disregards other interpretations and debates on meaning and significance in order to conform to the prevailing canons. In the case of behavioural economics, the social and institutional context is included in the analysis without questioning the rigid concept of rationality, thus viewing any phenomenon which escapes this straitjacket as "deviation", "error" or "anomaly."

It is therefore unsurprising that behavioural economics has been mobilised to justify policies which focus on improving decision-making, including individual and household decisions on credit and savings. In addition to those already mentioned, another example which illustrates this is the financial literacy programmes recently introduced in the more developed capitalist economies, whose aim is to prepare consumers to assume greater individual responsibility for planning in advance for retirement and protection against unforeseen events, objectives which have become more pressing since the financial crisis. ${ }^{8}$ Despite the merits of initiatives which help provide more information and financial education, the focus of the consumer protection policy in these areas of intervention

\footnotetext{
${ }^{8}$ In the case of Portugal, see the presentation of the National Financial Literacy Programme by the National Council of Financial Supervisors (2011).
} 
inevitably puts the onus on individuals, associating financial difficulties with uninformed and misguided choices made by consumers (Willis, 2008).

However, it cannot by any means be concluded from this that the problem lies in an excessive focus on internal individual processes, far less in disregarding the contributions of psychology, which also places a great deal of attention on individual decision-making processes. It is rather that the normative model of rationality in economics has restricted the incorporation of important contributions from psychology, selectively adopting those which best fit the prevailing conceptual and normative framework. In effect, psychology offers perspectives which are an alternative to rationality, including models which view the latter as contingent to context and see heuristics as cognitive instruments which are rational, efficient and appropriate for the context of choice, rather than obstacles to rational choice (Gigerenzer and Selten, 2001). These models also acknowledge a broader set of policy measures which include intervening in the institutional context in order to adapt it to the real circumstances and characteristics of human beings, rather than attempting to turn them into calculating machines by offering financial education. This, in turn, implies studying factors which extend beyond individual decision-making.

\section{The sociology of consumption and its shared origins with political economy}

In comparison with psychology, the apparent delay in the emergence of the sociology of consumption is perhaps surprising. The lack of any specialist section within the American Sociological Association is symptomatic of the position adopted by sociology, unlike psychology, where it has been recognised since 1962 . This claim only emerged in 2011, when the first proposal to create a sociology section was presented. Confirming the predominance of economics, psychology and marketing, the proposers cited the relevance of sociology to the study of consumption, arguing that it draws on themes which have always been at the heart of sociology, such as power, inequality, social differentiation, structure and agency relations and the interaction between individual behaviour and social phenomena (Cook et al., 2011).

It is therefore not surprising that it shares a set of theoretical concepts with political economy, which problematised early on the issue of the commodification of goods essential to human life and their growing importance in everyday life. Obvious cases in point are Capital by Karl Marx (1976 [1859]), which developed the influential idea of commodity 
fetishism, alluding to the transformation of social relations into an apparent relationship between objects, and The Theory of the Leisure Class by Thorstein Veblen (1973 [1899]), which proposed the productive concept of "social emulation" to designate the conspicuous consumption of goods as a means of displaying superior social status. A further relevant reference is Capitalism, Socialism and Democracy by Joseph Schumpeter (1970 [1943]), which highlights the process of the automatic expansion of emerging and created needs as higher standards of living are achieved. These are deemed to give rise to "heterogonic objectives," turning the state of satiety into a moving, and therefore unattainable, target. The common interests have continued to the present day in the area which brings economics and sociology together, namely the analysis of the interaction between individual and aggregate forms of behaviour, specifically in the work of the economists John Kenneth Galbraith (1998 [1958]), Fred Hirsh (1976) and Robert Frank (1985, 2007).

The causes for the apparent delay in establishing the sociology of consumption can be found in the "productivist bias" of the discipline, which may also apply to political economy, and which emphasized the "analytical categories, nomenclature and concepts forged by the 'founding fathers' of the social sciences in the late nineteenth century and early twentieth century, who sought mainly to deal with the problems and consequences of production and the social organization of an emerging industrial order." Consumption was therefore seen as "the endpoint of a production sequence [...], rather than as integrally intertwined with social-material processes" (Cook et al., 2011: 1-2). Sociology, favouring the study of production and distribution, considered the study of consumption to be of secondary importance, relegating it to more marginal fields such as culture, gender, family and inequality (Zelizer, 2005).

However, the social sciences soon began to draw on works that extended beyond the production, transaction and material dimensions and use of goods. One of the main references in the sociology of consumption is The Theory of the Leisure Class by Veblen, which, in focussing on the emerging North American middle class at the end of the $19^{\text {th }}$ century, argues that the position an individual occupies in an industrialised society depends on forms of displaying "pecuniary strength," namely leisure and conspicuous consumption, the latter determined by the "accepted standard of expenditure in the community or in the class to which a person belongs" (1973: 111). 
From this perspective, consumption does not reflect individual preferences or idiosyncrasies but mirrors the social context in which individuals find themselves, which supplies the prevailing norms for consumption, especially those set by the so-called leisure class. Nor does it conform to individual budget restrictions, given that any deviation from these consumer norms is seen as a serious affront to personal dignity. In effect, "conspicuous consumption of valuable goods is a means of reputability to the gentleman of leisure," since "the gentleman not only consumes beyond the minimum required for subsistence and physical efficiency, but his consumption also undergoes a specialisation as regards the quality of the goods consumed" (ibidem: 73-74). In addition, competition for social status means that the lower strata also seek social affirmation through conspicuous consumption and find themselves engaged in an incessant quest for the acquisition of goods associated with the social strata immediately above them, which in turn seek new luxuries in an attempt to preserve their social status. However, the search for status through consumption never ends, given the ongoing need for social affirmation and differentiation.

These contributions have been mobilised to explain the growing recourse to consumer credit in recent years, especially in the USA. According to Scott (2007), conspicuous credit can now be seen as the counterpart to Veblen's conspicuous consumption, with growing inequality and changes in the norms of consumption driving individuals towards credit, thus explaining the growing problem of over-indebtedness in US society.

In his work Distinction: A Social Critique of the Judgement of Taste (1979), Pierre Bourdieu, considered one of the main contemporary theoreticians of the sociology of consumption, explores the relationship between social classes and consumer practices, introducing into the analysis the role played by cultural and social factors in marking social differentiation. He argues that "the aesthetic disposition [...] is also a distinctive expression of a privileged position in social space," and that "being the product of the conditionings associated with a particular class of conditions of existence, it unites all those who are the product of similar conditions while distinguishing them from all others" (Bourdieu, 1984: 49). Bourdieu not only considers the relevance of these factors, but also attributes a key role to them, claiming that "aversion to different life-styles is perhaps one of the strongest barriers between the classes" (ibidem: 56). In Bourdieu we therefore find an analysis which complements that of Veblen, whilst also emphasising the role of the norms of consumption 
that not only explain consumption itself but also the use of credit which, in a context of rising inequality, does not depend on income and material wealth alone.

Other approaches emphasise the relevance of the social group to which the individual belongs. James Duesenberry (1949) analysed intraclass consumption comparisons, a phenomenon popularly described by the expression "keeping up with the Joneses." Focussing on post-war America, he argues that the rise of the middle class, in contributing to the growth of the suburbs, favoured neighbourhood social relations. These social relations, in relatively homogenous neighbourhoods in which female household work prevailed, favoured comparisons and aspirations based on a standard of living shared by those who interacted on a daily basis. From this perspective, relative economic homogeneity led to uniform consumer patterns amongst similar groups.

From the 1980s onwards, this model of horizontal social emulation began to change and was gradually replaced by a vertical emulation model, a transformation known as "new consumerism" (Schor 1998, 2002). Whereas in the previous model people learned about new consumer trends through neighbourhood relationships, the emulation model is now supplied by the rich and by celebrities who have become famous through the media, thus radically changing the level of consumer aspirations. The previous norm of "comfort" has now been replaced by a norm of "abundance" or "luxury." Juliet Schor associates these cultural changes with rising inequality in the distribution of income and wealth and the decline in neighbourhood relations following the gradual inclusion of women in the labour market, and their consequent replacement by the workplace and the media as the means of defining new life styles. From this perspective, the growing gap between income and levels of aspiration encouraged the use of credit, resulting in the gradual deterioration of household finances. Schor $(1993,1998,2002)$ also notes that the rise in North American household debt is linked to an increase in working hours, trapping people in an uninterrupted cycle of work and consumption.

Similarly, in The Affluent Society, John Kenneth Galbraith (1998 [1958]) emphasises the role played by advertising in creating needs and desires in the more developed capitalist societies, where the basic needs of individuals are already met and consumption is no longer a means of significantly improving wellbeing. Businesses therefore resort to increasingly aggressive marketing strategies to create the desire for increasingly sophisticated products. This growth in private consumption is deemed to have a damaging effect on the production 
of public goods - such as parks, libraries and museums - since it absorbs resources that could be rechanneled into the production of these assets.

In a work suggestively entitled The Joyless Economy: An Inquiry into Human Satisfaction and Consumer Dissatisfaction, Tibor Scitovski (1976) also examines the process of creating needs and desires in the more developed capitalist societies. Firmly anchored in the psychology of the 1950s and 1960s, he argues that the fulfilment of basic needs, i.e. pain relief and the pursuit of pleasure, or simply what he called comfort, does not meet all human needs. People also derive satisfaction from being challenged, i.e. from novelty. Scitovski's analysis thus shifts the field of study from the production of consumer goods traded on the market to other types of activities and interpersonal relationships and is considered the precursor of another emerging area of economics, the so-called economics of happiness (Pugno, 2012).

This incursion into the common ground between political economy and sociology reveals a critical vision of the consumer society which highlights the role of economic processes in the creation of superfluous needs, and the role of social differentiation in escalating sterile consumption that has socially undesirable results. The relationship between consumption and recourse to credit is analysed more rigorously in this context, extending beyond the relationship between consumption and income envisaged by conventional economics, or the relation between consumption and deviant behaviour of behavioural economics. However, these approaches have been criticised for portraying consumers as passive agents, conforming to the interests of the industry or aspiring to the current social model as if they were mere automatons.

Following the postmodern movement that pervaded the social sciences, and based on growing market segmentation and its corrosive effect on the homogeneity of the system for determining social status, the focus has shifted from production and producers to consumption and consumers. It now highlights the capacity of individuals to construct their own meanings autonomously and independently of the meanings intended by the industry or any other hegemonic structure. Instead of promoting uniformity, consumption is now seen as a source of creativity and social innovation. Schor (2007: 19-20) provides an illustrative description of this paradigm shift:

The "postmodern" consumer is a playful and adventurous individual, putting on and taking off roles like costumes from her or his eclectic closet, shunning conventional (upscale) status 
aspiration [...] the "good life" is no longer a matter of acquiring a well-defined set of consensual status symbols but is a project of individual self-creation. Studies of subcultures also rejected the trickle-down model on the basis of a growing tendency for consumer innovation to come from the social margins, as trends in fashion, music, art, and language were originating among poor inner city youths, rather than the wealthy.

However, by focussing on self-reported accounts of consumers, this approach encounters the reverse problem, veering towards the methodological individualism of conventional economics and also assuming that the acquisition of consumer goods in itself, and the plurality of meanings associated with this, contributes to individual wellbeing. Consumption is assumed to belong to the intimate sphere of the individual, understood as private, subjective and hedonistic, devoid of any political content and thus exempt from critical assessment. Standing at the opposite pole to the conventional vision of sociology, this perspective restricts consideration of the socio-economic factors relevant to an analysis of consumption and household debt. Moreover, both the conventional and the postmodern approaches omit the study of debt and its links to the evolution of consumer norms in contemporary capitalist societies, a subject to which recent analyses in political economy have paid particular attention.

\section{The political economy of consumption and household debt}

Rising household debt in the more advanced capitalist economies has attracted the attention of political economists, who position this important phenomenon within a broader set of profound socio-economic changes that have materialised in the growing influence of the financial sector (via its agents, processes and products) on the activities of households, business and states, in a process which critical literature has termed financialisation (Epstein, 2005; Ertuk et al., 2007; dos Santos, 2009; Lapavitsas, 2009; Montgomerie, 2009).

According to the Regulation School, these changes have weakened the "capital-labour compromise" characteristic of the Fordist regime of accumulation associated with the economic dynamism witnessed from the 1950s onwards in the USA, Europe and Japan, and the significant improvement in living conditions for workers in these countries (Boyer, 2000a, 2000b). This compromise was based on the so-called Fordist methods of production, i.e. the mass production of standardised goods and a relatively homogenous class of workers collectively organised in trade unions, benefiting from increased productivity in the form of wage increases. Parallel to this, the state also embraced new commitments, guaranteeing 
economic and social stability whether through public investments or the creation of social protection systems. The expansion of productive capacity was thus institutionally synchronised with the expansion of demand, based on the evolution of the "wage relationship," which contributed to the growth of large companies and the creation of oligopolies.

However, from the late 1960s onwards the political commitments and prevailing institutional arrangements began to be threatened by a fall in productivity and the replacement of the regime of intensive accumulation based on mass consumption with a socalled flexible regime of accumulation, in which production was internationalised, the oligopolies acquired new powers (namely financial) and the role of the state was reconfigured, leading to liberalisation, deregulation and the privatization of the economy. The Fordist "wage relationship," based on homogenous consumer patterns, was gradually dismantled, resulting in greater economic and social inequality. The production process, based increasingly on quality and innovation, not only promoted social differentiation through increasingly segmented production, but also the fragmentation of the labour market, with greater variability in contracts and wages. During this period a number of innovations also allowed for the creation of increasingly globalised financial markets, making national economies more vulnerable to fluctuations in the world economy (Boyer, 2000a, 2000b; Glyn, 2007).

Intensifying international competition, in turn, shook the previous system of oligopolistic competition and companies now began to compete through product differentiation and the breakdown of the capital-labour compromise, leading to the flexibilisation of the labour market and reductions in wage costs. The gradual incorporation of businesses within the capital markets meant that their management paid greater attention to the interests of shareholders, who lobbied for valuation of company share prices, and this became the new measure of entrepreneurial success (Crotty, 2005; Froud et al., 2006).

The capital-labour nexus thus became an adjustable variable in the face of the weakening economic and political power of the workforce, following the fragmentation of the labour market and the incorporation of the short-term imperatives of the capital markets within company strategies. The economic dynamism and full employment of the post-war era gave way to stagnation and unemployment. The slowdown in the world economy, in turn, put social protection systems under great pressure. As a result, individuals and households 
intensified their interactions with the financial sector, either by subscribing to private schemes for the provision of essential goods, such as pensions, or by resorting to credit for consumer goods or home ownership (Froud et al., 2006; Montgomerie, 2009).

With reference to the situation in the US, Montgomerie (2009) argues that stagnating incomes and rising social inequality led more households into debt in order to bridge the gap between income and expenditure. US household debt is therefore associated with the aforementioned consolidation of mass consumption in the post-war era, and the expansion of consumer credit is explained as an attempt to maintain a historical, politically constructed standard of living which was the hallmark of the American way of life. If on the one hand stagnating incomes led the US middle class to resort increasingly to credit to preserve the American lifestyle, on the other hand the shrinking of the welfare state and rising inequality in the distribution of income led the more affluent segments of the population to the capital markets and private social protection systems.

In short, drawing on sociological analyses of consumption, Montgomerie (2009) argues that the growing involvement of the financial sector in the lives of US families is the result of the deterioration of the socio-economic environment, in a society in which consumption is socially and politically very important. She also considers that the increasing financialisation of households translates into increasing household vulnerability. Their financial frailty has increased not only because debt now absorbs a substantially larger portion of their income, but also because, due to the financial crisis, many households are now confronting a fall in the price of houses bought with mortgages and the depreciation of their retirement savings. In the context of the current financial and economic crisis, the use of private debt rather than wage rises and public spending as a mechanism for sustaining consumption, which Crouch (2009) has termed "privatised Keynesianism," is seriously compromised (Barba and Pivetti, 2009; Tridico, 2012).

More recently, certain authors have emphasised that the increasing weight of the financial sector in everyday household life reproduces class, gender and ethnic inequalities (Roberts, 2013). However, these analyses focus on the USA and the United Kingdom and are difficult to apply to the European context, which has not witnessed such an acute and general deterioration in the living conditions of the labour force, and in which very different situations, in terms of the relationship between households and the financial sector, coexist (Crouch, 2012; Hein, 2012). In fact, the countries with the highest levels of debt in the 
European Union are those with the lowest levels of inequality and more robust social protection systems. This is the case in Denmark and Holland, where household debt is primarily the result of home ownership and is concentrated amongst the upper income brackets (Santos and Teles, 2013). It thus follows that the growing overlap between households and the financial sector is still a poorly understood phenomenon, and that its study should focus on the changing circumstances that drive different segments of the population towards the financial markets.

Another line of research, inspired by Marxism, focuses on the hegemonic power of finance, in particular the power hierarchy and relations underlying the credit market. According to Dos Santos (2009) and Lapavitsas (2009), the fact that companies were increasingly accessing the capital markets forced banks to redirect their business to households via housing loans. The liberalisation of the financial markets is considered to have played a crucial role in this process, enabling commercial banks to become involved in investment activities, in particular allowing them to transform bank loans (specifically mortgages) into securities and trade them on the capital markets. The banks were thus able to make use not only of a mechanism that released capital to provide new loans, but also a new risk dispersal instrument, believing that the securitisation of these loans would enable them to separate the business of granting loans from the associated risks by transferring this to the purchasers of securities who expected high future returns (Crotty, 2009). These changes were boosted by innovations in information technologies which not only allowed for better individual risk assessment but also the dispersal of the risk associated with credit across the financial markets. Credit facilities, specifically mortgages, were therefore extended to hitherto excluded sectors who could not offer guarantees against default. A highly lucrative market segment emerged, given the high interest rates charged and the extraordinary profits made from default penalties (Dymski, 2009). When house prices began to fall and interest rates rose, defaults occurred on a large scale, given that property values were unable to cover the housing loans. Instead of diluting credit risk via international investors, the spread of financial securities ended up by propagating the effects of the US real estate crisis to the international financial markets, culminating in the biggest economic and financial crisis since the Great Depression of 1929.

Before ending, it is important to refer to a line of research inspired by studies into science and society which focuses on the relationship between finance and everyday life, 
highlighting the process whereby the individual is established as his/her own entrepreneur, investing in his/her own life project in an ongoing search for profit opportunities that involve risk (Langley, 2009). This is a process that has been progressively promoted by states, given its essential role in reconfiguring the welfare state, which is increasingly transferring the responsibility and risk of future financial security to individuals (Finlayson, 2009). All these factors tend to create great instability in the everyday lives of households and increasing segmentation in society.

It is therefore clear that political economy calls for a broad framework of analysis, identifying a set of socio-economic changes that reveal the systemic causes of the expansion of the supply and demand for credit. Although it focuses on the Anglo-American situation, the political economy of household debt places household provision systems at the centre of the analysis, including the welfare state and the labour market. The literature also reveals the underlying interests behind the profound institutional changes, particularly those in the financial sector, which has acquired increasing economic and political power, acting not only as an intermediary in consumer decision-making but also as a service provider to households, specifically via private pension schemes. This analysis therefore stands at the opposite pole to conventional economics, rejecting the idea that extending the benefits of finance to the middle class and lower socio-economic brackets is the result of the democratisation of finance and the promotion of freedom of choice, together with autonomous and independent citizenship, ideas which are based on an unshakeable faith in the markets (Ertuk et al., 2007).

In opposition to this, political economy also takes the profound ongoing cultural changes into account, placing at the centre of the analysis the evolution of consumer norms, perceptions of the role played by the state, individuals and households in providing essential goods and services and, consequently, the concept of citizenship itself in increasingly financialised societies. Thus a clear understanding of household debt requires an interdisciplinary study that positions it within the ongoing cultural changes and powerful social constraints (such as inequality) that have been created by profound changes in contemporary capitalist societies. However, this work is still in a very embryonic stage, requiring not only analyses that address contexts other than the Anglo-American world, but also a deeper examination of the relationship between finance and reforms to the labour 
market and public systems for the provision of essential commodities such as housing and pensions, as well as their specific impact on the various sectors of society.

\section{Conclusion}

In the analysis of consumption and debt, the ongoing dialogue between economics and the other social and human sciences has brought to the fore issues that have always divided the social sciences, namely the dichotomies between approaches that take the individual as the unit of analysis and those which privilege social factors, or approaches that focus on identifying the configurations or mechanisms underlying human behaviour and social phenomena and those which are based on identifying meaning and significance.

Analyses which focus on the individual perceive consumption and debt as the result of decisions that are to a greater or lesser extent rational, and that take advantage of the expanding supply of new goods and new financing opportunities which separate the moment of consumption from the generation of income. Approaches that emphasise sociostructural changes point to the context in which decisions to consume or use credit are made, taking the evolution of social norms or the loss of the economic and political power of workers as explanatory factors for rising household debt.

These dichotomies naturally reflect the paradigmatic contrast between the proposals of conventional economics and those of political economy. Whilst the methodological individualism of the former favours dialogue with psychology, the focus on major changes in the contemporary capitalist system which is characteristic of political economy facilitates dialogue with dialogue with sociology. Conventional economics undervalues the effects of context on decision-making and thus maintains a view of consumption and debt that tends to make individuals accountable for their choices. Conversely, political economy, in focusing on major trends, tends to overlook the role of human agency.

These contrasting visions also represent different normative standpoints. Conventional economics usually favours the expansion of consumption and debt, associating them with a greater and improved capacity to satisfy individual subjective preferences. Political economy, on the other hand, tends to highlight their harmful effects, such as the wastefulness of conspicuous consumption and the growing vulnerability of households resulting from the instability of labour relations and wages in increasingly financialised economies. 
But both analyses overgeneralise the meaning and uniformity of the role played by the chosen explanatory factors. To a large extent this bias is the result of fragmented analyses which blur the capacity to take the various relevant factors and interactions into due consideration, namely the analysis of what is specific to each type of consumer commodity, as well as the differentiated way in which various consumer goods are acquired, used or displayed by different social groups, in addition to what is specific to each type of credit. For these reasons, Fine and Leopold (1993; see also Fine, 2002) consider that the study of consumption should address what differentiates rather than unites commodities, which should be seen not so much as consumer items but as the result of their constituent economic and social structures and processes. By the same token, the analysis of household debt should begin to focus on the distinctive and characteristic features of various types of debt and the differentiated involvement of various segments of the population with finance. Moreover, recent empirical work (Santos and Teles, 2013) has shown how the relationship between consumption and debt varies on a national scale. A contextual analysis should therefore consider the different national trajectories and the relatively subordinate position of each country within a contemporary international economy in which finance both standardises and differentiates various geographical contexts.

The analysis undertaken here also shows how household debt is still an insufficiently studied topic. It emerges only marginally in disciplinary analyses of consumption. However, political economy offers an analytical framework that allows for dialogue between the various disciplinary and interdisciplinary fields, drawing attention to the need to examine the way in which consumption of a wide range of goods and multiple forms of financing are linked to the shrinking of the welfare state and the loss of labour rights, and how these changes reflect and shape the values which govern collective and personal life.

Political economy should nonetheless dedicate more attention to the interaction between context and individual and household decision-making processes. The growing role played by the financial sector as an intermediary in individualised access to an increasing range of goods and services reinforces the importance of including this topic in the political economy research agenda, particularly given the current context of deepening instability in employment and the uncertainty surrounding social protection systems in many European countries. This is yet one more argument for an interdisciplinary approach that is capable not only of combining the relevant intellectual resources in an analysis of the multiple 
factors in question but, above all, of considering their interactions and, to paraphrase a wellknown expression, the circumstances that are specific to each case but not determined by it.

Translated by Sheena Caldwell

Revised by the authors and Teresa Tavares

\section{References}

Barba, Aldo; Pivetti, Massimo (2009), "Rising Household Debt: Its Causes and Macroeconomic Implications-A Long-period Analysis," Cambridge Journal of Economics, 33(1): 113-137.

Bertola, Giuseppe; Disney, Richard; Grant, Charles (eds.) (2006), The Economics of Consumer Credit. Cambridge, MA: MIT Press Books.

Bourdieu, Pierre (1984), Distinction: A Social Critique of the Judgement of Taste. Trans. Richard Nice. Cambridge, Mass.: Harvard UP. [First published in 1979. La distinction. Critique sociale du jugement. Paris: Minuit].

Boyer, Robert (2000a), "Is a Finance-led Growth Regime a Viable Alternative to Fordism? A Preliminary Analysis," Economy and Society, 29(1): 111-145.

Boyer, Robert (2000b), "The Political in the Era of Globalization and Finance: Focus on Some Regulation School Research," International Journal of Urban and Regional Research, 24(2): 274322.

Calder, Lendol (1999), Financing the American Dream: A Cultural History of Consumer Credit. Princeton: Princeton University Press.

Camerer, Colin; Loewenstein, George (2004), "Behavioral Economics: Past, Present, Future," in Colin Camerer, George Loewenstein and Matthew Rabin (eds.), Advances in Behavioral Economics. Princeton and Oxford: Princeton University Press, 3-51.

Campbell, John Y. (2006), “Household Finance," The Journal of Finance, 61(4): 1553-1604.

Cook, Daniel T.; Miller, Laura; J., Schor; Juliet B.; Stillerman, Joel (2011), "Section Proposal to American Economic Association: The sociology of consumers and consumption." Accessed on 02.04.2013, at http://csrn.camden.rutgers.edu/pdf/consumersconsumption ASA section proposal.pdf.

Conselho Nacional de Supervisores Financeiros (2011), Plano Nacional de Formação Financeira 20112015. Lisboa: BdP, CMVM; ISP.

Crotty, James (2005), "The Neoliberal Paradox: The Impact of Destructive Product Market Competition and Impatient Finance on Nonfinancial Corporations in the Neoliberal Era," PERI Research Brief, 2003-5. Political Economy Research Institute, University of Massachusetts at Amherst.

Crotty, James (2009), "Structural Causes of the Global Financial Crisis: A Critical Assessment of the New Financial Architecture," Cambridge Journal of Economics, 33: 563-580.

Crouch, Colin (2009), "Privatised Keynesianism: An Unacknowledged Policy Regime," British Journal of Politics \& International Relations, 11(3): 382-399.

Crouch, Colin (2012), "Employment, Consumption, Debt, and European Industrial Relations Systems," Industrial Relations, 51(S1): 389-412.

Cynamon, Barry Z.; Fazzari, Steven M. (2008), "Household Debt in the Consumer Age: Source of Growth-Risk of Collapse," Capitalism and Society, 3(2): 1-30. 
Dymski, Gary (2009), "Racial Exclusion and the Political Economy of the Subprime Crisis," Historical Materialism, 17: 149-179.

dos Santos, Paulo (2009), "At the Heart of the Matter: Household Debt in Contemporary Banking and the International Crisis," Ekonomiaz, 72: 54-77.

Duesenberry, James (1949), Income, Saving and the Theory of Consumer Behavior. Cambridge, MA: Harvard University Press.

Epstein, Gerald (ed.) (2005), Financialization and the World Economy. Northampton: Edward Elgar Press.

Erturk, Ismail; Froud, Julie; Johal, Sukhdev; Leaver, Adam; Williams, Karel (2007), "The Democratization of Finance? Promises, Outcomes and Conditions," Review of International Political Economy, 14(4): 553-575.

Fine, Ben; Leopold, Ellen (1993), The World of Consumption. London: Routledge.

Fine, Ben (2002), The World of Consumption: The material and cultural revisited. London: Routledge.

Finlayson, Alan (2009), "Financialisation, Financial Literacy and Asset-based Welfare," British Journal of Politics and International Relations, 11(3): 400-421.

Frank, Robert H. (1985), Choosing the Right Pond: Human Behavior and the Quest for Status. New York: Oxford University Press.

Frank, Robert H. (2007), Falling Behind: How Rising Inequality Harms the Middle Class. Berkeley: University of California Press.

Frederick, Shane; Loewenstein, George; O'Donoghue, Ted (2002), "Time Discounting and Time Preferences: A Critical Review," Journal of Economic Literature, 40(2): 351-401.

Friedman, Milton (1957), A Theory of the Consumption Function. Princeton: Princeton University Press.

Froud, Julie; Sukhdev, Johal; Leaver, Adam; Williams, Karen (2006), Financialization and Strategy: Narrative and Numbers. London: Routledge.

Haugtvedt Curtis P.; Herr, Paul M.; Kardes, Frank R. (eds.) (2008), The Handbook of Consumer Psychology. New York: Taylor \& Francis Group.

Hein, Eckhard (2012), "Finance-dominated Capitalism, Redistribution and the Financial and Economic Crises - A European Perspective," MPRA Paper No. 35903. Accessed on 02.04.2013, at http://mpra.ub.uni-muenchen.de/35903.

Hirsch, Fred (1976), Social Limits to Growth. Cambridge, MA: Harvard University Press.

Galbraith, John Kenneth (1998), The Affluent Society. Boston MA: Houghton Mifflin [1 ${ }^{\text {st }}$ ed.: 1958].

Gigerenzer, Gerd; Selten, Reinhard (eds.) (2001), Bounded Rationality: The Adaptative Toolbox. Cambridge: MIT Press.

Glyn, Andrew (2007), Capitalism Unleashed. New York: Oxford University Press.

Guiso, Luigi; Sodini, Paolo (2012), "Household Finance. An Emerging Field," CEPR Discussion Papers, 8934.

Kahneman, Daniel; Tversky, Amos (1979), "Prospect Theory: An Analysis of Decision under Risk," Econometrica, 47(2): 263-292.

Kahneman, Daniel; Slovic, Paul; Tversky, Amos (eds.) (1982), Judgment under Uncertainty: Heuristics and Biases. New York: Cambridge University Press. 
Laibson, David (1997), "Golden Eggs and Hyperbolic Discounting," The Quarterly Journal of Economics, 112: 443-477.

Laibson, David (1998), "Life-cycle Consumption and Hyperbolic Discount Functions," European Economic Review Papers and Proceedings, 42(5): 861-887.

Langley, Paul (2008), "Financialization and the Consumer Credit Boom," Competition \& Change, 12(2): 133-147.

Langley, Paul (2009) The Everyday Life of Global Finance: Saving and Borrowing in Anglo-America. Oxford: Oxford University Press.

Lapavitsas, Costas; dos Santos, P. (2008), "Globalization and Contemporary Banking: On the Impact of New Technology," Contributions to Political Economy, 27: 31-56.

Lapavitsas, Costas (2009), "Financialised Capitalism: Crisis and Financial Expropriation," Historical Materialism, 17(2): 114-148.

Levine, David; Kehoe, Timothy J. (2001), "Liquidity Constrained Markets versus Debt Constrained Markets," Econometrica, 69: 575-598.

Loewenstein, George (1996), "Out of Control: Visceral Influences on Behavior," Organizational Behavior and Human Decision Processes, 65: 272-92.

Loewenstein, George; Thaler, Richard (1989), "Anomalies: Intertemporal Choice," Journal of Economic Perspectives, 3(4): 181-193.

Loewenstein, George; O'Donoghue, Ted; Rabin, Matthew (2003), "Projection Bias in Predicting Future Utility," Quarterly Journal of Economics, 118: 1209-1248.

Macinnis, Debbie; Folkes, Valerie S. (2010), "The Disciplinary Status of Consumer Behavior: A Sociology of Science Perspective on Key Controversies," Journal of Consumer Research, 36: 899914.

Markowitz, Harry (1952), “The Utility of Wealth,” Journal of Political Economy, 60: 151-158.

Marx, Karl (1976), Capital. Vol. 1. New York: Vintage [1 ${ }^{\text {st }}$ ed.: 1859].

Milonakis, Dimitris; Fine, Ben (2009), Political Economy to Economics: Method, the Social and the Historical in the Evolution of Economic Theory. London/New York: Routledge.

Modiagliani, Franco; Brumberg, Richard (1954), "Utility Analysis and the Consumption Function: an Interpretation of Cross-Section Data," in Kenneth K. Kurihara (ed.), Post-Keynesian Economics. New Brunswick: Rutgers University Press, 388-436.

Montgomerie, Johnna (2009), "The Pursuit of (Past) Happiness? Middle-class Indebtedness and American Financialisation," New Political Economy, 14(1): 1-24.

Pugno, Maurizio (2012), "Scitovsky's The Joyless Economy and the Economics of Happiness," European Journal of the History of Economic Thought, vol. ahead-of-p, no. ahead-of-p, 1-26.

Roberts, Adrienne (2013), "Financing Social Reproduction: The Gendered Relations of Debt and Mortgage Finance in 21st Century America," New Political Economy, 18(1): 21-42.

Santos, Cordeiro Ana; Teles, Nuno (2013), "Empirical Report on Cross-national Comparative Analysis of Household Financial Behaviour - Recent Trends," mimeo.

Schumann, David W.; Haugtvedt, Curtis P.; Davidson, Edith (2008), "History of Consumer Psychology," in Curtis P. Haugtvedt; Paul M. Herr; Frank R. Kardes (eds.), The Handbook of Consumer Psychology. New York: Taylor \& Francis Group, 3-28.

Schor, Juliet (1993), The Overworked American: The Unexpected Decline of Leisure. New York: Basic Books. 
Schor, Juliet (1998), The Overspent American: Why We Want What We Don't Need. New York: Harper Perennial.

Schor, Juliet (2002), "Understanding New Consumerism: Inequality, Emulation and the Erosion of Well-being," PSW-paper, 2002/2 (April).

Schor, Juliet (2007), "In Defense of Consumer Critique: Revisiting the Consumption Debates of the Twentieth Century," The Annals of the American Academy of Political and Social Science, 611: 1630.

Scitovski, Tibor (1976), The Joyless Economy: An Inquiry into Human Satisfaction and Consumer Dissatisfaction. New York: Oxford University Press.

Schumpeter, Joseph (1970), Capitalism, Socialism and Democracy. London: George Allen \& Unwin [1 ${ }^{\text {st }}$ ed.: 1943].

Scott, Robert (2007), "Credit Card Use and Abuse: a Veblenian Analysis," Journal of Economic Issues, XLI(2): 567-574.

Shefrin, Hersh; Thaler, Richard H. (1988), "The Behavioral Life-Cycle Hypothesis," Economic Inquiry, 26(4): 609-643.

Starr, Martha (2007), "Saving, Spending, and Self-Control: Cognition versus Consumer Culture," Review of Radical Political Economics, 39(2): 214-229.

Stigler, George J.; Becker, Gary S. (1977), "De Gustibus Non Est Disputandum," The American Economic Review, 67(2): 76-90.

Thaler, Richard H. (1992), The Winner's Curse: Paradoxes and Anomalies of Economic Life. Princeton and Chichester: Princeton University Press.

Thaler, Richard; Benartzi, Shlomo (2004), "Save More Tomorrow" Increase Employee Saving," Journal of Political Economy, 112(1): 167-187.

Tobin, James (1958), "Liquidity Preference as Behavior Towards Risk," Review of Economic Studies, 25(1): 65-86.

Tridico, Pasquale (2012), "Financial Crisis and Global Imbalances: Its Labour Market Origins and the Aftermath," Cambridge Journal of Economics, 36(1): 17-42.

Tversky, Amos; Kahneman, Daniel (1974), “Judgment and Uncertainty: Heuristics and Biases," Science, 185: 1124-1131.

Tversky, Amos; Kahneman, Daniel (1981), "The Framing of Decision and the Psychology of Choice," Science, 211: 453-458.

Veblen, Thorstein (1973), The Theory of the Leisure Class. Boston: Houghton Mifflin [1 $1^{\text {st }}$ ed.: 1899].

Willis, Lauren E. (2008), “Against Consumer Financial Literacy Education," lowa Law Review, 94(1): 197-285.

Zelizer, Viviana (2005), "Culture and Consumption," in Neil J. Smelser; Richard Swedberg (eds.), The Handbook of Economic Sociology. Princeton: Princeton University Press, 331-354. 